ISSN 1112-9867

Available online at

http://www.jfas.info

\title{
EVALUATION OF STRUCTURAL SYSTEMS IN PRECAST CONCRETE BUILDINGS BY USING STRUT-AND-TIE METHOD
}

\author{
S.Vakili Haji Agha ${ }^{1}$ and M.Pasha Zanussi ${ }^{2}$ \\ ${ }^{1}$ Department of Civil Engineering, University of Eyvanekey, Iran \\ ${ }^{2}$ Department of Civil Engineering, Islamic Azad University,Sari Branch, Iran
}

Published online: 11 June 2016

\begin{abstract}
In general, the precast concrete is the type of concrete that constructing, casting and curing in the standard factory conditions with high quality and then it will be transported with proper equipments and then it will be installed in the final position. In fact, the precast concrete buildings are the combined of several types of structural systems. So we can mix them with several methods until to reach the useful structural system. Because the structural connections and connecting regions of precast concrete elements, are subjected to concentrated forces with high values, so in this article we try to explain the usage of tie-and-strut method and the possibility of using this method in design of existing connections between precast concrete components.
\end{abstract}

Keywords: structural systems; precast; strut-and-tie method; concrete buildings.

Author Correspondence, e-mail: shahroozvakili@yahoo.com

doi: http://dx.doi.org/10.4314/jfas.8vi2s.73

\section{INTRODUCTION}

In addition to several advantages of precast concrete structures, such as reducing time of constructing, producing the standard and high quality components in factory conditions, 
economical usage and ability to using them repeatedly (formwork system), the possibility of using the larger segments and the less necessity to skilled workers, these types of structures have some limitations too, which include:

- Size of precast units

- Less variety in position of openings

- Limited spaces to storage of precast units

According to the type of precast structure, we can use of several design methods which one of them is the strut-and-tie method. In general, strut-and-tie method is a one of the suitable tools that used to design the connecting regions and check the properability of the balance conditions in the final limit state.

This method, usually, specify the force path along of structural connection. So it helps to designers to have a better understanding of the connections behaviour.

In fact, precast concrete structures, are the combination of several types of structural systems. We can combine this systems with various methods. The common systems in the precast concrete structures are followed:

- Beam to column systems (beam and column elements, connections)

- Floor and ceiling systems (ceiling and floor elements, connections)

- Load bearing walls systems (wall elements, connections)

- Façade systems (façade elements, connections)

In general, these options are not enough, so, architects and structural engineers, use other elements in constructing of precast buildings that consist of rigid portal frames and arches.[3] The building facades are often load bearing and they provide the lateral stability. But we can consider them as a non bearing elements. Another types of precast concrete systems are followed:

- Framing systems (frame elements, connections)

- Cellular systems (cell elements, connections)

\section{BEAM AND COLUMN SYSTEMS}

In general, although in beam and column systems, beams are more similar to roof rafter 
beams, but in fact, they are a combination of beams and columns. In the figure 1-a, the column height is considered higher than the height of storey. The figure 1-b, shows the skeletal frame system. The required connections in this system are followed:

- Beam to column

- Beam to beam

- Column to column

- Column to foundation

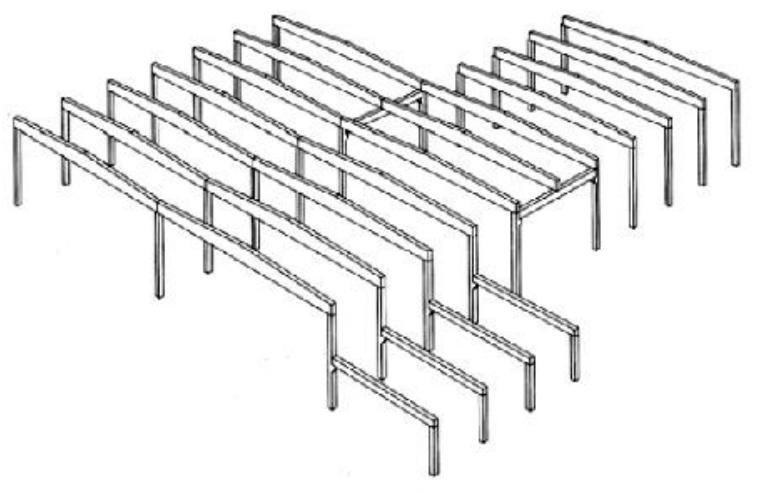

a)

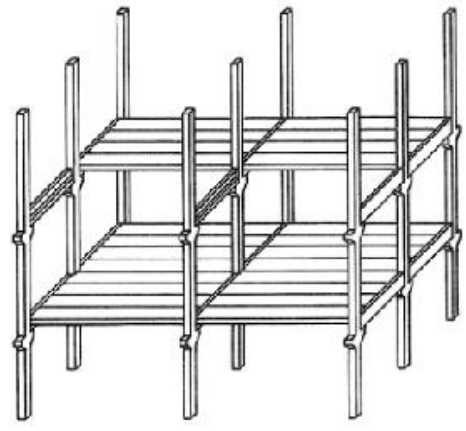

b)

Fig.1. Beam/column systems (a) single-storey columns (b) multi-storey columns

\section{CEILING AND FLOOR SYSTEMS}

The main duty of ceiling and floor systems is the transferring the vertical load to structural elements that have a suitable resistance against vertical loads. Furthermore, precast ceiling and floors, usually, consider as a main structural stabilization system, to transfer the horizontal loads to diaphragm. The common types of flooring systems are hollow core and double tees floors.

We usually, use the double tees in ceiling systems. The connections of this systems are followed:

- Slab to slab connection, in internal longitudional joints

- Slab to edge of element, in longitudional edge

- Slab to slab connection in the internal support

- Slab to end support connection 
Flooring systems elements don't have enough resistance separately against loads. But the interaction degree between elements or adjacent elements will be favourable. To be insured of having the suitable interaction between adjacent elements, and according to the followed reasons, the flooring connections must act such as shear key.

- Lateral distribution of loading effects

- Concentrated loads conditions

- Preventation of create vertical displacements in longitudional joints

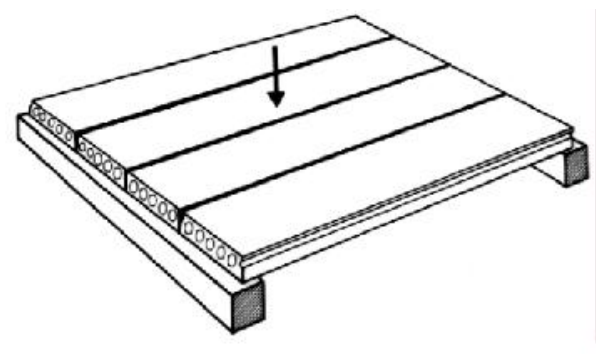

a)

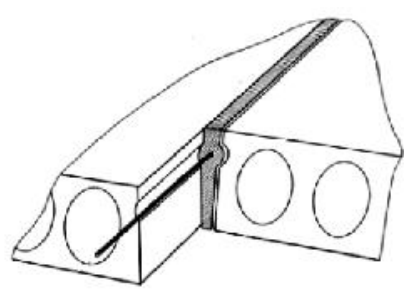

b)

Fig.2. Interaction and transverse distribution of adjacent hollow core precast elements

(a) distribution of transverse loads (b) shear key details

In the flat composite floorings, that called as half-slab, there are precast concrete flooring plates, act as a form and then remain in the composite flooring completely. Composite behaviour depends on the way of shear force transferring in horizontal joints that provided between the preacst components.

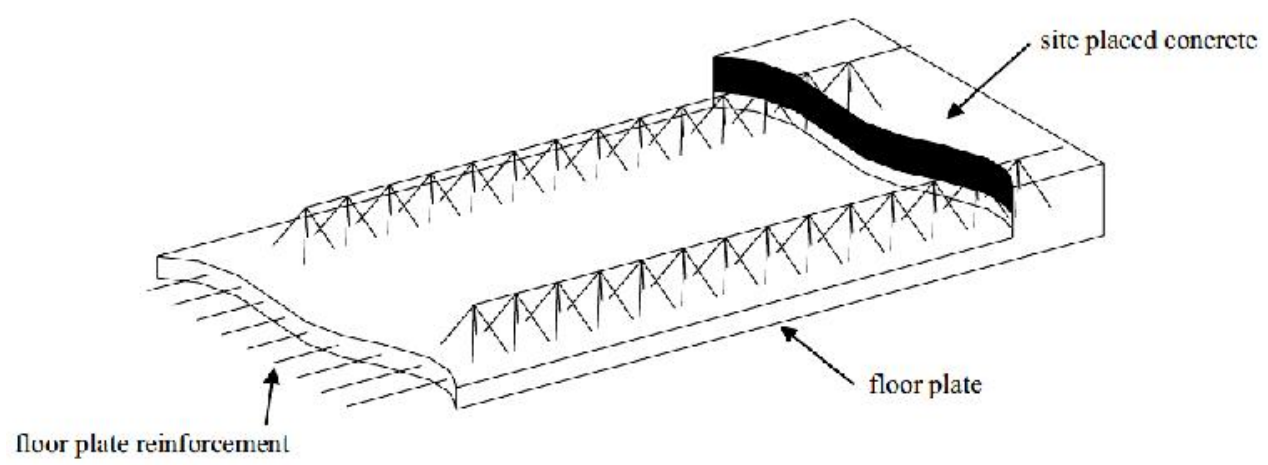

Fig.3. Composite floor plate floor system with lattice girders 


\section{WALLS SYSTEMS}

The main types of precast wall systems are shown in the figure 4. Usually, the walls are classificated to the main categories as followed:

1) Load bearing walls

2) Non-load bearing walls

The main usage of the load bearing walls is support the elements loads such as flooring, ceiling and beams. The figure 4 shows the examples of non loading walls. The connections that are used in this type of walls are:

- Wall to wall connection in internal and external vertical joints

- Wall to wall connection in internal and external horizontal joints

- Wall to foundation joint

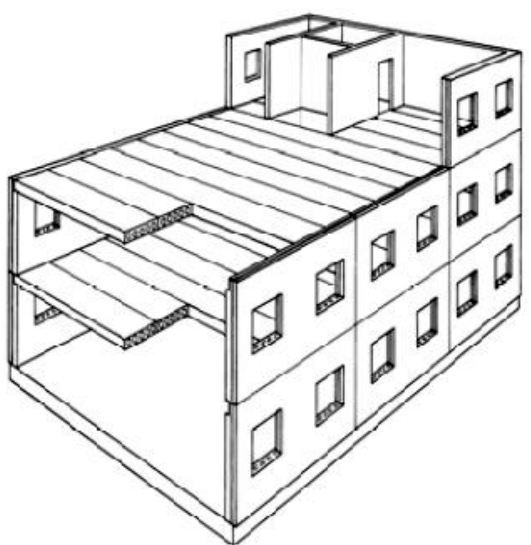

a)

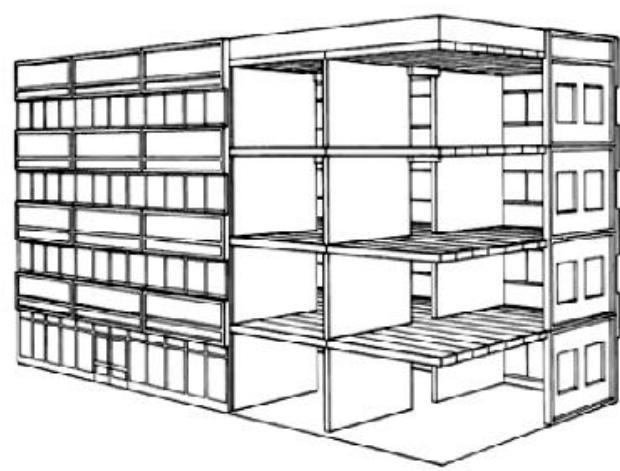

b)

Fig.4. Examples of load bearing wall systems (a) facade load bearing walls (b) transverse load bearing walls

Usually, the non bearing walls are designed to support the self loadings so the connections that provided in horizontal joints, should be supported the weight of above walls.

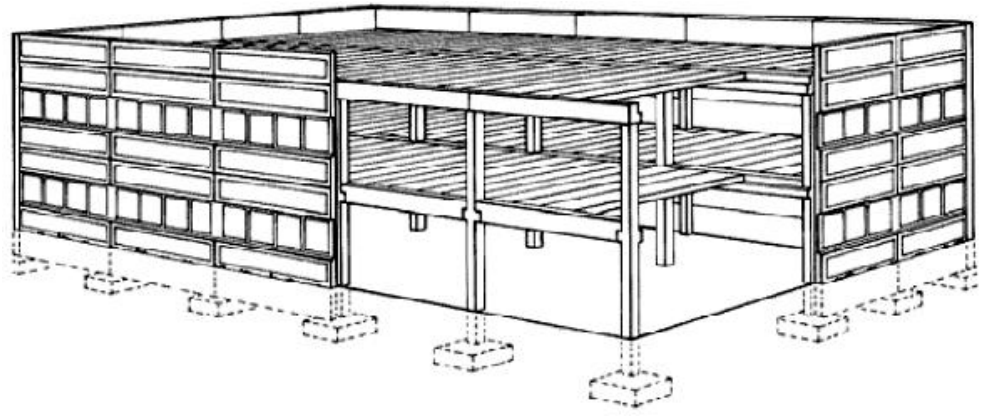

Fig.5. Example of facade non-load bearing walls 
Therefore, the façade non bearing walls may be connected to the adjacent load bearing system until the main system can be able to support the dead load of each wall units. We can consider the precast walls as a part of stabilization system to resist against the horizontal loads. In this condition, the precast wall should behave as structural components (Figure 6).

So, the existing interaction in the wall should be controlled properly with usage of structural connections which have enough ability to support the compressive, shear and tension forces. In general, in the precast concrete structures we can classify the wall system in two categories as followed:

1) Transverse wall system

2) Longitudional wall system

In the transverse wall system, the load bearing walls are situated prependicular to the longitudional direction of building and addition to support the gravity loads that transfer from one-way slab to it, they provide the resistance of building against lateral seismic forces in the transverse direction. In the longitudional wall system, the main load bearing walls are situated parallel to longitudional direction of building. In addition to support the gravity loads that transfer from one-way slabs,they are providing the resistance of building against seismic loads in the longitudional direction of building.

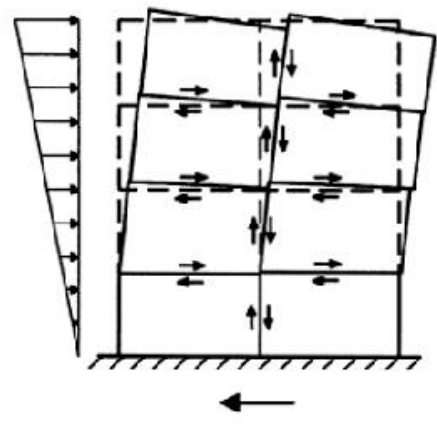

a)

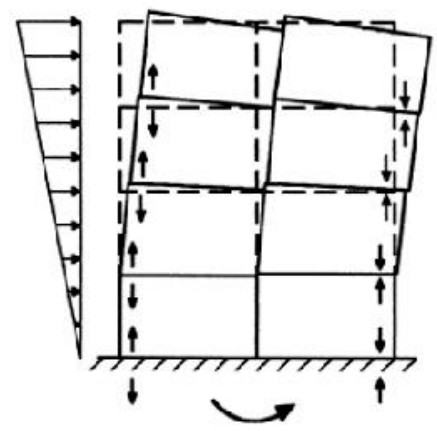

b)

Fig.6. In-plane action of precast wall (a) shear forces (b) compressive and tensile forces

\section{MOMENT RESISTING SYSTEM}

Precast concrete moment resisting systems are usually used in skeletal or portal systems that have a fundamental role in providing the stability of system.we can reach to this by mixing the H,L elements or portal frames and with usage of homogenous connections in the crossing 
of beams and columns.the elements are usually connect to each other in some parts untill there is not any requirement to high bending resistance.

\section{CELLULAR SYSTEM}

Cellular precast concrete system is generated by combining the close or open hollow core elements with U or L shapes (Figure 7)

So the usage of cellular elements is common for the specific part of structure.

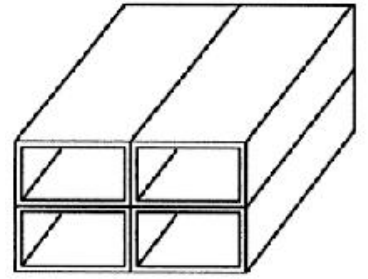

a)

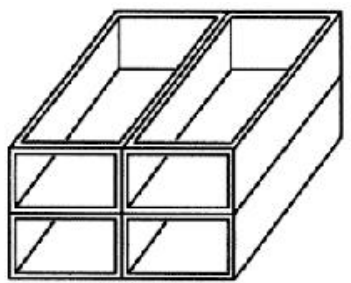

b)

Fig.7. Cellular precast system (a) closed cellular units (b) open units with U shape section

\section{DESIGN OF CONNECTING REGIONS BY USAGE OF STRUT-AND-TIE METHOD}

Structural connections and connecting regions of precast concrete elements, are subjected to concentrated loads with high values. When these forces are transferring along the connection and adjacent elements, they distribute along the section.

The creating of deviation in forces (For example the changing of forces direction), and even the stress distribution, will be caused to create the transverse stress with high values. If the tension resistance of concrete increases, the cracking will be appeared in these regions.

If there wont be enough attention to these crackings that caused the high damaging and it will create a kind of limitation in the connection capacity.

The strut-and-tie method is based on the theory of elasticity. In conditions that the critical connecting regions have sufficient plastic deformation capacity, understanding of its behaviour will be simpler. The designer should choice the strut-and-tie model somehow that the stress zone in the cracked reinforced concrete was simulation and in the condition that design load is existing, keep the its balance. In most cases, the limitations related to allowed deformations are based on the flexibility of precast element. 

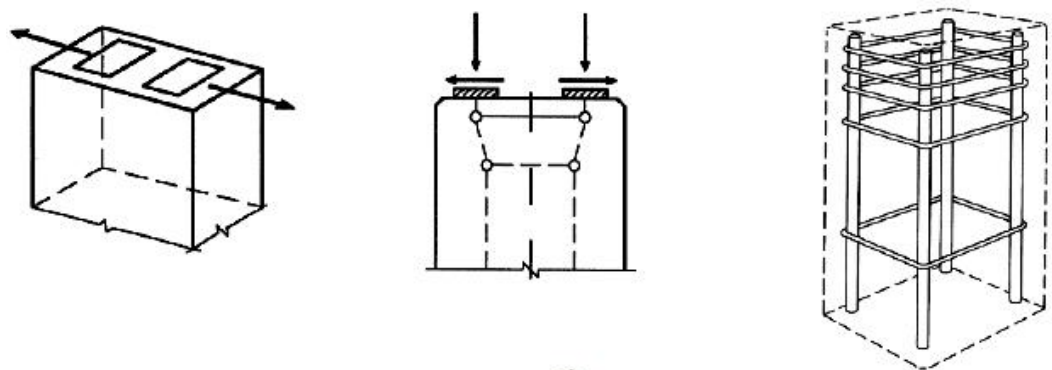

a)
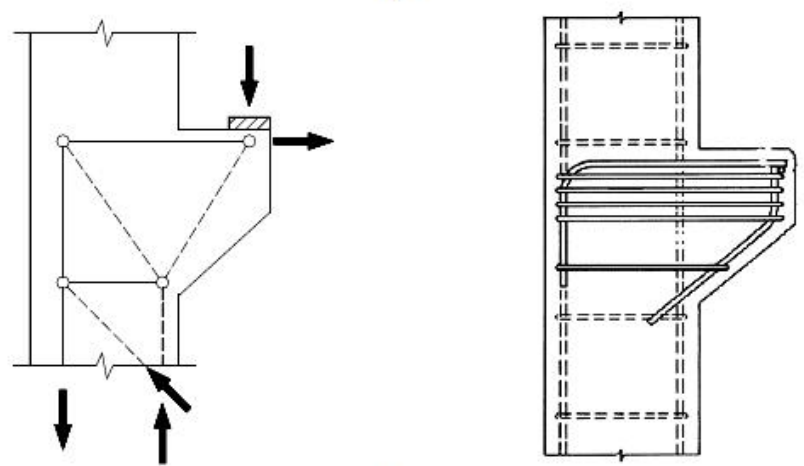

b)

Fig.8. The connecting regions in precast elements are defined as discontinuous regions

(a) design and detailing of column head (b) design and detailing of a column corbel

The members of the strut-and-tie system, i.e. ties, struts and nodes, are checked with regard to their strengths. As long as the chosen stress field is in equilibrium with the applied load and no critical regions are overstressed above their strengths, the stress field is theoretically a possible one. However, the actual stress-field in the structure under the applied loads may be different, since the structure itself, by means of the detailing that the designer has provided, can find a more effective way to carry the load. In this way the actual solution will theoretically be on the safe side.[3]

For small loads the concrete remains uncracked and the reinforcement has only a very small Influence on the behaviour. In this stage the concrete has an almost linear elastic response and the behaviour of the connection zone could be examined by linear analysis based on theory of elasticity for a homogenous material. Linear analysis results in one unique solution, i.e. a stress field. Typical for this solution is that when the load increases, the stress field configuration remains the same and the magnitude of the stresses increases in proportions to the applied load.

However, when the load increases the concrete will crack. The reinforcement placed across cracks will now have a significant influence on the behaviour. The actual stress field will 
depend on the actual stiffness properties, which in turn will depend on the actual state of cracking and the reinforcement arrangement. Therefore, different reinforcement arrangements will result in different stress fields, which in turn will deviate from the one, found by linear analysis. Under increasing loads the cracking will develop more and more, which results in a continuous change of the stiffness properties and of the corresponding stress field configuration. This is known as stress redistribution due to cracking. At high loads critical points in the connections zone will be stressed to their strengths. Both concrete in compression and steel has a plastic behaviour at high strains. Due to this plastic behaviour in some critical points, the stiffness properties of the connection zone will change again, which results in a change of the stress field. When the load increases further, the stresses of these critical points cannot increase any more, but will be limited to the strength that was provided by the designer. This change of the stress field configuration is known as plastic stress redistribution. Plastic redistribution continues with increasing load until the plastic strength is reached in so many critical points that the load cannot be increased further. This load should correspond to the design load and the final stress field will be the one that was simulated by the strut-and-tie model. It is finally reached by successive stress redistribution. Hence, the structure has to follow the intention of the designer by using the capacities that are provided. For this reason the design problem can be solved by alternative designs, as long as they all fulfil the basic equilibrium conditions [2].

The plastic stress redistribution will require substantial plastic deformation capacity of the critical points that reach their strength early. The theory of plasticity assumes that the materials have an ideally plastic behaviour with unlimited plastic deformation capacity. In this respect there is a deviation between theory and reality. Reinforced concrete has a limited plastic deformation capacity. The knowledge about the plastic redistribution, need for plastic deformations, and plastic deformation capacity in connection zones with alternative designs is very limited. For this reason the designer should be careful in the choice of strut-and-tie models to avoid models that will require large plastic redistribution [2]. 


\section{CONCLUSION}

In general, the proper choice of structural system in precast concrete structures is very important. For this reason, for obtain better structural behaviour, we can use of combined structural systems. Because the all of structures are subjected to several loads and forces, so exact understanding of types of forces, such as tensional, compressive and shear, by designer is very important. One of the best common methods that are used in precast concrete structures is strut-and-tie method. In this method, the member that subjected to tensile force is called tie, and the compressive member is called strut. Because of this method are based on theoty of elasticity, so the choice of strut-and-tie model. It should be noted that the stress zone in cracked reinforced concrete will be simulated.

\section{REFERENCES}

[1] PCI handbook, 7 Editions, 2010.

[2] FIB. Guide to good practice-structural connections for precast concrete buildings. International Federation for Structural Concrete, bulletin no. 43, Lausanne, 2008.

[3] KICT. Precast modular superstructure system. Korea Institute of Construction Technology, Interim Report, 2012.

[4] Kaneko Y, Connor J, Triantafillou T, Leung C. Fracture mechanics approach for failure of concrete shear key. I: Theory. J Eng Mech 1993, 119:681-700. http:// dx.doi.org/10.1061/(ASCE)0733-9399(1993) 119:4(681).

\section{How to cite this article:}

Vakili Haji Agha S and Pasha Zanussi M. Evaluation of structural systems in precast concrete buildings by using strut-and-tie method . J. Fundam. Appl. Sci., 2016, 8(2S), 587-596. 